\title{
Issues in role
}

development for the CNS in oncology

\section{by Dauna Crooks and Carolyn Ingram}

\section{Abstract}

The authors' experiences as oncology clinical nurse specialists (CNSs) led to discussion and exploration of common issues in role success and failure. The complexity of the role demands that the CNS examine system entry issues, his or her base of support and conflicting demands and expectations.

This article focuses on issues pertaining to development, maintenance and evaluation of the clinical nurse specialist role. Role definition and strategies to develop and maintain both direct and indirect practice components of the CNS role are discussed. Particular attention is paid to the need for clarity of expectations and negotiations at system entry, as well as during role development and evaluation.

\section{Introduction}

The purpose of this article is to share the authors' experiences in developing their roles as oncology clinical nurse specialists (CNSs), and to provide an understanding of the complexity of the related issues. Recommendations will be offered which address common issues arising during critical periods in CNS role development, specifically, at system entry, during maintenance activities, and at evaluation. As a result of reading this article, a CNS seeking employment will be better equipped to determine the "fit" between the agency and his or her areas of interest and expertise. CNSs currently in practice or entering practice will find a mirror with which to reflect their progress, and a base of common issues for consideration in negotiation of role change or development.

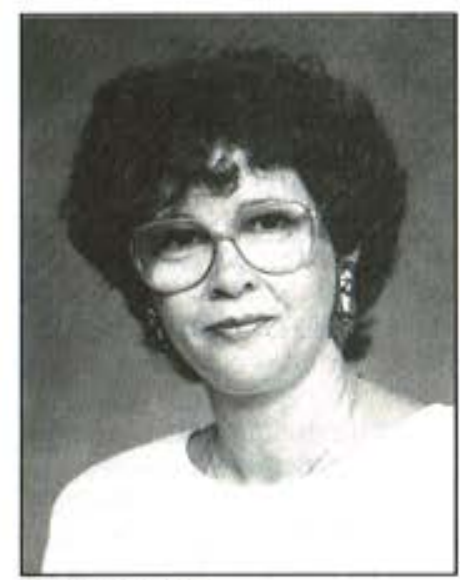

Dauna Crooks

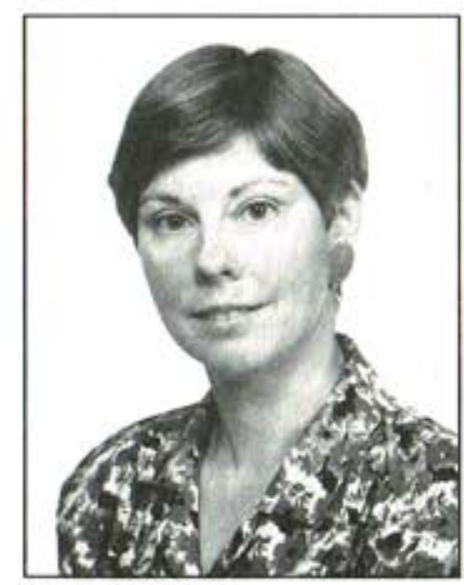

Carolyn Ingram

\section{The CNS role}

Since the 1960 s, advances in technology, increased complexity of treatment regimes, and a heightened awareness of the interplay of psychosocial variables with health and recovery created a demand for an advanced practitioner in nursing (Werner, Bumann \& O'Brien, 1988). The clinical nurse specialist role evolved in response to this demand.

The CNS has been described in the literature as a registered nurse with masters or doctoral preparation in a defined nursing speciality (ANA, 1980; Andreoli, 1987; Diers, 1985). A central feature of the CNS role is specialized, client-centred practice (ANA, 1986; RNAO, 1990; Beecroft \& Papenhauser, 1989). Hamric (1989) stresses the practice component as essential to the definition of the CNS role, and asserts that at least 50 per cent of a CNS's time should be spent in direct practice activity. Recognition of the CNS's expertise in nursing practice forms the basis for consultation with and referrals from colleagues in health care (Beecroft \& Papenhauser, 1988). Specialization through advanced education at masters or doctoral levels, in addition to providing in-depth knowledge in a speciality, develops advaneed skills in clinical judgment, scholarly enquiry, leadership and research. These are the primary characteristics that set the CNS apart from nurse clinicians, nurse practitioners and nurse educators with other qualifications (Benner, 1985; Diers, 1985). Expertise in clinical decision-making facilitates the primary role of expert clinical practitioner and promotes development of the secondary roles of role model, change agent, consultant, educator and researcher (Werner, Bumann \& O'Brien, 1988).

Noll (1987) asserts that essential qualities for the CNS are: Excellent listening skills, leadership abilities, role modelling, goal setting, trouble shooting and evaluation. Personal experience has shown that in addition to these qualities, the CNS also needs boundless energy, enthusiasm and optimism, especially when the role is new or under-utilized, or when the role is undergoing change and renegotiation.

\section{LE DÉVELOPPEMENT DU RÔLE DES SPÉCIALISTES EN SOINS INFIRMIERS ONCOLOGIQUES CLINIQUES: DES INTÉRROGATIONS}

\section{ABRÉGÉ}

L'expérience des auteurs en tant que spécialistes en soins infirmiers cliniques oncologiques les a amenés à discuter et à explorer les problèmes communs expliquant la réussite ou l'échec de leur role. La complexité du rôle exige que le ou la spécialiste en soins infirmiers cliniques examine de près les problèmes au niveau de l'entrée dans le système, sa base de soutien et les conflits qui existent entre les exigences et les attentes.

Cet article traite des questions qui se rapportent au développement ou au maintien du role de spécialiste en soins infirmiers cliniques. Il présente la définition du role et des stratégies de développement et de maintien des composantes directes et indirectes de la pratique du role des spécialistes. II s'intéresse particulièrement au besoin qu'il y a d'être clair au niveau des attentes et des négociations tenues au moment de l'entrée dans le système, tout au long du développement du rôle et lors de l'évaluation.

Dauna Crooks is currently a doctoral student at the University of New York in Buffalo and is on leave from the Faculty of Nursing at McMaster University in Hamilton. She is a Maurice Legault Fellow-Canadian Cancer Society. Carolyn Ingram is a lecturer with the McMaster University School of Nursing. Both authors have held positions as CNSs in oncology. 
A strong but realistic sense of self, and belief in the multifaceted nature of the role are also crucial. In addition, the CNS should understand how to assess the agency, gain acceptance for the CNS role and initiate change in nursing practice (Hodges, Poteet \& Edlund, 1985; Radke, McArt, Schmidtt \& Walker, 1990).

\section{Issues in system entry}

A needs assessment completed by the agency should identify major areas of deficiency and strength within the oncology service, and clearly identify the need to hire an advanced nursing practitioner (Harrell \& McCullough, 1986). During the hiring and entry processes, the potential CNS must determine if his or her personal and professional goals and areas of expertise fit with the organizational needs, values and goals. The expertise and interests of the CNS should help define his or her role, however, organizational fit is also necessary, as it provides the security needed for the role to evolve. Determining "fit" is a complex issue for the CNS considering that the needs and expectations of patients, nursing staff, nurse manager and administration are very likely to differ. The CNS needs to be sure that enough questions have been asked and factors considered to decide if the expertise he or she brings to the position is adequate to meet those demands.

Once an applicant decides to assume an oncology CNS position, negotiation for a "system entry" and orientation period is essential. Orientation activities include introduction to policy, procedure, philosophy and certification for specialized skills, and may require two days to six weeks for completion. System entry activities, however, may require six months to one year depending upon the expertise and experience of the CNS as a practitioner, educator and researcher. These activities include learning the broader system, familiarizing oneself with the cultures of the nursing units involved, determining the base of support in nursing and elsewhere, and gaining acceptance within the agency. The value of an entry period has been clearly demonstrated in cvaluations of the role, and through experiential feedback of CNS colleagues. This period assists in fostering feelings of comfort and belonging for the $\mathrm{CNS}$, and provides an adequate opportunity to examine the fit between the expectations of the CNS and the agency. Yasko (1983) identified the main stressor for the oncology CNS as lack of psychological support from the system. CNSs, therefore, need to create a support base early in their employment (Paulen, 1985).

The broader system is best learned through the mentorship of the administrator. When the administrator makes introductions to nursing and other colleagues, support for the CNS is made visible, and value is placed on the CNS role. Supportive working relationships lay the groundwork for future goal-setting, and support for CNS decisions.

System entry time taken with individual nursing units accomplishes several goals. In addition to learning the culture of the unit, the CNS identifies the "movers" on the unit whose experience or enthusiasm can be tapped when clinical activities are initiated. With the support of these key staff members, later projects and research in areas of interest to the staff are more likely to be successful.

Oncology is a broad clinical field and the CNS is unlikely to have had experience in all areas. System entry is a time for the CNS to define and meet his or her learning needs. Experience has shown that clinical competency demonstrated during the entry period is essential to CNS acceptance at the staff nurse level. The entry period on each unit also allows the CNS to observe the roles and functions of oncology team members, and determine a unique practice role for him or herself.

Another key player at the unit level is the nurse manager. While the nurse manager offers a key to entry at the unit level, keeping the CNS apprised of current patient problems or issues, the CNS in return offers collegial support for the difficult decisions the head nurse must make in running the unit, and assists in long-term planning. Together, they provide direction for staff in patient care, and plan to address gaps in patient care delivery.
The entry period allows the administrator to assess whether the CNS possesses the necessary skills in negotiation, collaboration and consultation. Concurrently, the CNS assesses the support of the administrator. The CNS needs continued support as the role develops, so it is imperative that everything possible be done to earn and maintain this. For example, the CNS should initially conduct a needs assessment focused on his or her specific areas of expertise. Areas of difference and areas of similarity between the agency needs and CNS expertise must be discussed with the administrator to determine priorities for action.

\section{Issues in the direct practice role}

Direct CNS practice must be focused on improving quality of patient care through provision of care, role modelling of care behaviours for staff and family members, or advocacy activities which protect patient rights and meet specific patient needs. If the emphasis of the CNS role shifts to education, administration or research, Hamric (1989) asserts that the title clinical nurse specialist is no longer applicable and should not be used.

As an expert clinician, the CNS needs to be afforded expanded authority and autonomy for practice. (Topham, 1987). Autonomy implies independent practice with direct responsibility and accountability for outcomes. Authority implies primary responsibility for a specific client population. There is potential for confliet with physicians and nurse managers who have traditionally held much of the control and responsibility for patient care. The CNS, therefore, must create a role which is strongly collaborative, yet provides care which clearly reflects his or her ability and clinical nursing expertise.

Through graduate education, the CNS is exposed to theories which expand the views of care, patients and nursing. Although technical expertise may be required in CNS practice, for example in managing a patient with a venous access device or complex dressings, broader assessment of the patient's ability to learn and take control of his bealth is more in keeping with the knowledge and skill of the CNS. For example, the CNS may begin by teaching tracheostomy care but moves on to assess the adaptation necessary for home management, and maintenance of the patient's lifestyle. Support is given beyond the unit encounter as the CNS provides consultation to the patient, family and community health care providers.

Complex developmental issues are addressed by the CNS as well, through the use of advanced interpersonal and counselling skills. Issues of altered sexuality, appearance, or role function are a few examples of these developmental issues.

Advocacy is clearly demonstrated in assisting patients or families to make decisions regarding initiation, continuation or termination of treatment.

Role modelling is evidenced by the manner in which the CNS approaches the patient, family and other colleagues, which encourages staff to do the same. $\mathrm{A} \mathrm{CNS} \mathrm{questions} \mathrm{and} \mathrm{reports} \mathrm{in} \mathrm{a} \mathrm{holistic} \mathrm{manner}$ that prompts enquiry and values the uniqueness of patients. Presentation of ideas to patients or physicians models problem-solving behaviour and assertiveness for staff.

CNS practice is a means of demonstrating and documenting obvious patient needs which will lead to the development of new patient programs. Examples of such programs recently developed include ambulatory pain pump programs, skin care rounds or breast cancer support groups.

Multidisciplinary rounds are helpful in establishing CNS credibility if they provide a forum in which to discuss patient issues and to determine whose expertise best meets specific client needs. The CNS may initiate these rounds or, alternatively, work through a physician to identify a patient group requiring the CNS's specific nursing expertise. The CNS must be articulate in describing the full potential of the role, in order to demonstrate the need for advanced, holistic nursing practice within the physician's patient group. Appropriate examples of physician referral to a CNS include patient teaching about therapy, support for depressed or newly diagnosed clients, or sexual counselling. 
The nursing staff is a more appropriate source of CNS referral than physicians, but is often difficult to utilize effectively. While the CNS must be visible, credible and assertive in seeking nursing referrals across an agency, staff nurses must have ample opportunity to test their relationships with the CNS. Utilization is enhanced if staft recognise the CNS as possessing expertise in one identified area of care, such as pain management or symptom control. Recognition for psychosocial expertise or patient education skills is often slower to develop. The CNS may be perceived as having time for "extras" when staff are pressured with the quantity of tasks they must accomplish. It is beneficial for CNSs with interests in psychosocial care or patient education to capitalize on this reality, so that $\mathrm{CNS}$ and staff nurse roles become complementary. The nursing referral system offers the CNS global access to client issues, and therefore allows a broader base of functioning than physician referrals are likely to provide. Investment of energy in developing this network is returned manyfold.

Ultimately, the CNS will survive only if the major expectations of all caregivers working with a population of clients agree (Baron, 1983). If the CNS is given adequate opportunity to define and express the role, it will become apparent that a multitude of possibilities exist in both direct and indirect care activities. (Baker, 1987; Harell \& McCullough, 1986).

\section{Issues in indirect functions}

The direct functions of the CNS as a practitioner, role model and patient advocate are complemented by indirect functions which include change agent, consultant, resource, educator, researcher and liaison (Ryan-Merritt, Mitchell \& Pagel, 1988). Each indirect role builds upon, and in turn supports, the primary role of direct caregiver. Balancing direct and indirect functions on one hand and organizational needs and demands on the other remains the single most difficult issue for the CNS.

\section{Educator function}

As an educator, the CNS may provide expertise, consultation and evaluation in the development of special educational programs or projects offered within the agency. Established and routine programs, for example CPR training, IV certification or general orientation, are most cost-effectively delivered by nurse educators. The CNS role is not to deliver these programs but to provide consultation and mentorship to the providers. Similarly, the CNS's educational activities with staff are best kept case-specific or related to issues in oncology nursing practice. Difficulties arise, however, when the education and training needs of staff are the priority of the agency, and the CNS's patient care role is viewed as secondary. In this situation, the CNS must weigh the possibilities for expansion of the practice component once basic educational needs are met. In some cases, it may be advantageous to the CNS to operate this way initially to become known. The obvious disadvantages in accepting these conditions are that the CNS must recreate and redefine the role at a later date, and that confusion with the role of clinical educator is likely. Expectations of others based on an earlier role definition may result in conflict and resentment.

\section{Researcher function}

Research interests of the CNS should be discussed early, although they may not take priority in the first year. Expectations for the CNS to conduct research should be clarified and administrative support and commitment sought when research ideas are generated (Cronewett, 1986). Flexibility of time to plan and carry out research is important as is protected time for writing and presentation of findings. The CNS can make the advantages of nursing research clear and tangible to administrators by demonstrating how it will validate nursing actions and heighten the profile of agency nursing activities. Rescarch activities provide additional data for CNS evaluation related to: Time management, relationship of questions studied to goals for the oncology service, ability to work with others and ability to develop and complete a project.
Clinical agencies in major Canadian centres are beginning to hire nurse researchers, which is a positive step in provision of mentorship for the research of CNSs. When on-site resources for research are non-existent, the CNS must either possess strong research expertise or learn to network with others who have those skills. Networking, in addition to research mentoring, provides a peer group for role development, problem solving and support. Liaisons with university faculty, in particular, provide expertise in research methodology and access to secretarial and computer resources in return for access to a client population, current clinical expertise, and most importantly, the researchable clinical questions.

\section{Consultation function}

The consultation role of the CNS stems from advanced knowledge, skill and an ability to develop alternative approaches to a problem identified by nursing staff, administrator or other health care workers. Consultation activities include working with a group to define and refine the problem or issue and to select an approach from a range of possibilities. Support is provided through the implementation and evaluation phases. One example of consultation involves situations where staff nurses have trouble dealing with the behaviour of a "difficult patient". The CNS gathers data from every available source to determine the real or most important issues. Staff are assisted to create a workable approach that satisfies the needs of all concerned. Examples of difficult behaviour may range from patients changing IV flow rates to a mother who denies the need to tell her children about her imminent death.

Consultation overlaps other direct and indirect functions and may also be demonstrated in networking, committee work, and multidisciplinary group meetings, (Cleary, Courtade \& Kerr, 1986; Johny, 1986; Rogers \& Trimnell, 1987). CNS Consultation may be extremely useful in dealing with staff crises, such as death of patients or patients with difficult family situations. Administration may request

\section{Learn to belp where it matters most.}

\section{Oncology Nursing - Post Diploma Certificate Program}
Our program offers a professional and flexible way to address the specialized needs of nurses who care for cancer patients and their families. Specifically. our program can offer you:
- Flexibillty - part-time, day/evening. On-site courses avaliable - full-time, on demand.
- Hands-on experience - practicum course to meet indlvidual learning neөds in a wide variety of settings.
- Up-to-date knowledge and skills training - the latest information required for comprehensive nursing care.

For more information on this or other post-diploma nursing programs, please call Kay Glennie, Co-ordinator at (416) 698-4097 or write to us at:

CENTENNIAL COLLEGE

P.O. Box 631. Station A. Scarborough, Ontario MIK 5E9

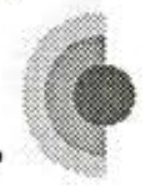


the CNS to consult on proposed changes in nursing services or implementation of theory-based practice. This type of activity clearly depicts the problem-solving, assessment and decision-making abilities of the CNS.

\section{Evaluation issues}

By understanding that evaluation begins on the date of hiring, the CNS assures that continuous negotiation and sharing of progress occurs routinely. Healthy administrative relationships are fostered when the CNS is open and honest about job-related concerns, and difficulties in meeting negotiated deadlines. Evaluation criteria pertinent to each of the CNS subroles need to be developed. The CNS, ideally, participates in creating evaluation criteria which truly reflect the position and the responsibilities involved. The onus is on both the CNS and administrator to collect data for evaluation from as many sources as possible. Documentation of goals, progress and changes in priorities are important data for evaluation of role effectiveness. Dilution of any aspect of the direct or indirect role functions is documented and strategies are presented by the CNS to refocus his or her activity. Quarterly updating and renegotiation of goals cannot be emphasized enough, as it is very difficult to predict institutional climate or goals beyond that time frame.

Evaluation remains a problem in Canadian agencies in that CNSs have often developed their roles in isolation, and their functioning is quite divergent from $\mathrm{CNS}$ to $\mathrm{CNS}$ and agency to agency. Diversity in

\section{References}

1. Andreoli, K.G. Specialization and graduate curricula: Finding the fit. Nursing and Health Care, 8, 1987, 64-9.

2. American Nurses' Association. Council of Clinical Nurse Specialists: The role of the CNS. Kansas City, Missouri: American Nurses' Association, 1986.

3. American Nurses Association. Nursing: A social policy statement. Kansas City, Missouri: American Nurses' Association, 1980.

4. Baker, P.O. Model activities for the clinical nurse specialist role development. Clinical Nurse Specialist, 1, (3), 1987, 119-123.

5. Barrow, A.M. The Clinical Nurse Specialist as consultant. In Hamric, A. and Spross, J. (eds), The Clinical Nurse Specialist in Theory and Practice. New York: Grune \& Stratton, 1983.

6. Beecroft, P.C. \& Papenhauser, J.L. Who is a clinical nurse specialist? Clinical Nurse Specialist, 3, (3), 1989, 103-104.

7. Beecroft, P.C., \& Papenhauser, J.L. What is a specialist? Clinical Nurse Specialist, 2, (3), 1988, 109-112.

8. Benner, $\mathrm{P}$. The oncology clinical nurse specialist as a coach. Oncology Nursing Forum, 12, (2), 1985, 40-44.

9. Cleary, N., Courtade, S.S., \& Kerr, D. The clinical nurse specialist: A valued consultant. Nursing Administrative Quarterly, 10, (1), $1986,48-50$.

10. Cronewett, L.R. The research role of the clinicial nurse specialist. Journal of Nursing Administration, 16, 1986, 10-11.

11. Diers, D. Preparation of practitioners, clinical specialists and clinicians. Journal of Professional Nursing, 1, 1985, $41-47$.

12. Hamric, A.B. History and overview of the CNS role. In Hamric, A.B. \& Spross, J. (eds), The Clinical Nurse Specialist in Theory and Practice, 2nd ed, Philadelphia: Saunders Pub. Co., 1989.

13. Hamric, A.B. CNS role evaluation. Oncology Nursing Forum, 12, (2), 1985, 62-66.

14. Hamric, A.B. Role development and functions. In Hamric, A. \& Spross, J. (eds), The Clinical Nurse Specialist in Theory and Practice. New York: Grune \& Stratton, 1983.

15. Harrell, J.S. \& McCullough, S.D. The role of the clinical nurse specialist: Problems and solutions. Journal of Nursing Administration, 16, (10), 1986, 44-48. itself is a positive attribute that attests to the initiative of CNSs to create roles independently. Defining commonalities, however, enhances acceptance and aids employers and practitioners in defining global expectations for practice and evaluation. Development of role definitions by provincial and national interest groups will provide helpful evaluation guidelines for the future.

\section{Conclusions}

It is obvious that the CNS, no matter how experienced, cannot perform all direct and indirect functions simultaneously, or within the course of a single year. Hamric (1989) suggests that the CNS plot out a critical path for activities, to assess and maintain synchrony of personal and institutional goals. Role failure has commonly been attributed to unrealistic expectations of the CNS and discrepancy of expectations among other players early in the role (Yasko, 1983). Administrative and unit support must be tangible and overt and is the responsibility of both the CNS and his or her colleagues. Implicit here is clarity of goals and expectations, which are determined and maintained through honest direct communication.

The CNS role is very complex and demanding. CNSs must use all the skill at their disposal to develop and maintain the trust, confidence and base of support needed for role survival. The outcome, however, is well worth the effort involved.

16. Hodges, L.C., Poteu, G.W. \& Edlund, B.J. Teaching clinical nurse specialists to lead .... and to succeed. Nursing and Health Care, 6, 1985, 192-196.

17. Johny, A. The consultant role for the CNS. Nursing Administration Quarterly, 10, (2), 1986, 72-76.

18. Laudermilk, L. Role ambiguity and the clinical nurse specialist. Nursing Connections, 3, (1), 1990, 3-12.

19. Noll, M.A. Internal consultation as a framework for clinical nurse specialist practice. Clinical Nurse Specialist, 1, (1), 1987, 46-50.

20. Paulen, A. Practice issues for the oncology clinical nurse specialist. Oncology Nursing Forum, 12, (2), 1985, 37-39.

21. Poteet, G.W., \& Branyan, M.E. Clinical nurse specialist: Not every graduate nursing student qualifies. Nurse Educator, 11, 1986, 4.

22. Radke, K., McArt, E., Schmidtt, M., \& Walker, E.K. Administrative preparation of clinical nurse specialists. Journal of Professional Nursing, 6, (4), 1990, 221-228.

23. Registered Nurses' Association of Ontario. Draft Three: Clinical Nurse Specialist Interest Group statement on the Clinical Nurse Specialist, (available from RNAO, 33 Price Street, Toronto, Ontario, M4W 1Z2).

24. Rogers, M. \& Trimnell, J. Maximizing use of the clinical nurse specialist as consultant. Nursing Administration Quarterly, 12, (1), 1987, 53-58.

25. Ryan-Merritt, M.V., Mitchell, A. \& Pagel, I. Clinical nurse specialist and operationalization. Clinical Nurse Specialist, 2, (3), 1988, 13-137.

26. Topham, D.L. Role Theory in relation to the role of the clinical nurse specialist. Clinical Nurse Specialist, 1, (2), 1987, 81-84.

27. Welch-McCaffery, D. Role Performance issues for clinical nurse specialists. Cancer Nursing, 9 (6) 1986, 287-294.

28. Werner, J.S., Bumann, R.M. \& O'Brian, J.A. Clinical nurse specialization: An annotated bibliography. Clinical Nurse Specialist, 2, (1), 1988, 14-15.

29. Yasko, J. A survey of oncology clinical nurse specialists. Oncology Nursing Forum, 10, (1), 1983, 25-30. 